\section{References}

' Fear CN, Mutton DE, Berry AC, Heckmatt JZ. Dubowitz V Chromosome 15 in Prader-Willi syndrome. Dev Med Chila Neurol 1985;27:305-11.

2 Schweizer D. Ambros P. Andrle M. Modification of DAPI binding on human chromosomes by prestaining with a DNAbinding oligopeptide antibiotic, Disamycin A. Exp Cell Res 1978;111:327-32

${ }^{3}$ Clarren SK, Smith DW. Prader-Willi syndrome-variable severity and recurrence risk. Am J Dis Child 1977;131:798-800.
${ }^{4}$ Hawkey CJ, Smithies A. The Prader-Willi syndrome with a $15 / 15$ translocation - case report and review of the literature. J Med Genet 1976;13:152-7.

5 Butler MG, Meaney FJ, Palmer CG. Clinical and cytogenetic survey of 39 individuals with Prader-Labhart-Willi syndrome. Am J Med Genet 1986;23:793-809.

Correspondence to Mr D Mutton, South East Thames Regional Genetics Centre, Guy’s Tower, Guy’s Hospital, London SE1 9RT.

Received 18 December 1986

\title{
Green or blue light phototherapy for neonates with hyperbilirubinaemia
}

\author{
H AYYASH, E HADJIGEORGIOU, I SOFATZIS, H DELLAGRAMMATICAS, AND \\ E SIDERIS
}

2nd Department of Paediatrics, University of Athens, Leto and M. Eliades Maternity Hospitals, Athens, and Biology Division N.R.C. 'Democritos', Athens, Greece

SUMmary A total of 262 neonates were treated with green $(350-650 \mathrm{~nm})$ or blue $(300-600 \mathrm{~nm})$ light phototherapy for a similar length of time. There was no significant difference in the rate of bilirubin photodegradation between the groups.

The possibility of using equally effective but safer spectral areas than the conventional $420-490 \mathrm{~nm}$ (blue part of the spectrum), in the treatment of neonatal jaundice is currently being investigated. It has been shown that green light is more effective than white in reducing serum bilirubin concentrations in preterm neonates. ${ }^{1}$

The purpose of the present study was to evaluate the efficacy of green versus blue light in reducing serum bilirubin in term and preterm neonates with hyperbilirubinaemia.

\section{Patients and methods}

Standard 20 watt sylvania F20T12G (green) or F20T12B (blue) fluorescent tubes were mounted on to conventional phototherapy units with five tubes each to provide the light source. The emission spectra were estimated with a Baush-Lomb 250 monochromator. The radiance of the lamps was measured from $50 \mathrm{~cm}$ away with a research IL 700 radiometer. The integrated emission energy was 0.326 milliwatt for the green light and 0.261 milliwatt for the blue light. A total of 262 neonates with jaundice of unknown aetiology were included, overt haemolysis having been excluded. They were separated into two groups according to their gestational age; 200 were born at term ( $\geqslant 37$ weeks) and 62 before term ( $<37$ weeks). They were then randomly allocated into two subgroups to receive either green or blue phototherapy (Table 1).

Table 1 Clinical and laboratory characteristics of the neonates

\begin{tabular}{|c|c|c|c|c|}
\hline \multirow[t]{2}{*}{ Characteristics } & \multicolumn{2}{|c|}{ Full term neonates } & \multicolumn{2}{|c|}{ Preterm neonates } \\
\hline & $\begin{array}{l}\text { Green light } \\
(n=100)\end{array}$ & $\begin{array}{l}\text { Blue light } \\
(n=100)\end{array}$ & $\begin{array}{l}\text { Green light } \\
(n=31)\end{array}$ & $\begin{array}{l}\text { Blue light } \\
(n=31)\end{array}$ \\
\hline Gestational age (weeks) & $38 \cdot 88(0 \cdot 131)$ & $38.99(0.127)$ & $34 \cdot 70(0 \cdot 374)$ & $34.58(0 \cdot 340)$ \\
\hline Birth weight $(\mathrm{g})$ & $3391(43)$ & $3397(44)$ & $2418(90)$ & $2304(80)$ \\
\hline $1 / 2$ body surface $\left(\mathrm{cm}^{2}\right)$ & $1063(12 \cdot 7)$ & $1055(9 \cdot 2)$ & $838(25 \cdot 5)$ & $832(20 \cdot 5)$ \\
\hline Age at the start of phototherapy (hours) & $105 \cdot(0)(2 \cdot 62)$ & $98.53(3.09)$ & $87.45(4.93)$ & $83.73(5 \cdot 52)$ \\
\hline Duration of phototherapy (hours) & $42.68(2 \cdot 74)$ & $49 \cdot 88(3 \cdot(2)$ & $53 \cdot 26(5 \cdot 52)$ & $53.29(5.90)$ \\
\hline
\end{tabular}

Values are given as mean (SD): none of the differences were significant at the $5 \%$ level 
Table 2 Serum bilirubin measurements

\begin{tabular}{|c|c|c|c|c|}
\hline \multirow[t]{2}{*}{ Serum bilirubin measurements } & \multicolumn{2}{|c|}{ Full term neonates } & \multicolumn{2}{|c|}{ Preterm neonates } \\
\hline & $\begin{array}{l}\text { Green light } \\
(n=100)\end{array}$ & $\begin{array}{l}\text { Blue light: } \\
(n=100)\end{array}$ & $\begin{array}{l}\text { Green light } \\
(n=31)\end{array}$ & $\begin{array}{l}\text { Blue light } \\
(n=31)\end{array}$ \\
\hline Rate of rise before phototherapy $(\mu \mathrm{mol} / \mathrm{h})$ & $3 \cdot 27(0 \cdot 22)$ & $3 \cdot 32(0 \cdot 19)$ & $3 \cdot 32(0 \cdot 63)$ & $3 \cdot 16(0 \cdot 46)$ \\
\hline At start of phototherapy $(\mu \mathrm{mol} / \mathrm{l})$ & $288(2 \cdot 5)$ & $284(3 \cdot 2)$ & $251(12 \cdot 7)$ & $227(9 \cdot 3)$ \\
\hline Rate of fall during phototherapy $(\mu \mathrm{mol} / \mathrm{h})$ & $3 \cdot 27(0 \cdot 22)$ & $2 \cdot 86(0 \cdot 17)$ & $2 \cdot 91(0 \cdot 38)$ & $2.50(0.39)$ \\
\hline Rate of fall during phototherapy $\left(\mu \mathrm{mol} / \mathrm{h} / \mathrm{cm}^{2} / \mathrm{mW} \times 10^{-5}\right)$ & $935(56)$ & $1036(61)$ & $1088(148)$ & $1136(196)$ \\
\hline At the end of phototherapy $(\mu \mathrm{mol} / \mathrm{l})$ & $246(3 \cdot 23)$ & $245(3 \cdot 08)$ & $214(9.54)$ & $192(8.41)$ \\
\hline Rate of rise (postphototherapy) rebound $-\mu \mathrm{mol} / \mathrm{h}$ ) & $0.24(0.07)$ & $0 \cdot 31(0 \cdot 10)$ & $0.60(0 \cdot 24)$ & $0.40(0 \cdot 12)$ \\
\hline
\end{tabular}

Values are given as mean (SD): none of the differences were significant at the $5 \%$ level.

Informed consent was obtained from the parents of those neonates who were to receive green phototherapy. The serum bilirubin concentration was measured every six hours before and during phototherapy and for 48 hours after stopping the treatment. Measurements were made on capillary samples using a bilirubinometer (American Optical Corporation). Phototherapy was stopped when two consecutive reductions in bilirubin concentration had been obtained. The quantum efficiency of bilirubin photodegradation ( $\mathrm{mg} /$ hour $/ \mathrm{cm}^{2} / \mathrm{milliwatt}$ ) was estimated, taking into account the differential emission energy of green and blue fluorescent lamps. The results were analysed using Student's two tailed $t$ test.

\section{Results}

There were no significant differences in the clinical characteristics between the two groups (Table 1).

The results are presented in Table 2 . There were no significant differences between the phototherapy groups in the rate of fall of serum bilirubin concentrations, the duration of phototherapy, and the serum bilirubin concentration at the end of treatment. There was no significant difference in the rebound rise in serum bilirubin concentrations after phototherapy between the two groups.

\section{Discussion}

The wavelengths with the greatest photodegrading effect on bilirubin are between 420 and $490 \mathrm{~nm}$. In cultures of procaryotic and eucaryotic mammalian cells exposure to this range of wavelengths results in the highest number of DNA breaks, mutation, and sister chromatid exchanges. ${ }^{2}$ Sister chromatid exchanges were also found in lymphocytes in peripheral blood of jaundiced neonates receiving blue light phototherapy. ${ }^{3}$ The fact that these photobiological changes are reduced after exposure to wavelengths greater than $500 \mathrm{~nm}$ led to the evalua- tion of phototherapy using other parts of the spectrum. Green light is more effective than white, and equally as effective as the special blue light in reducing serum bilirubin in preterm neonates. ${ }^{14}$ The present study included more jaundiced full and preterm neonates than previous studies and it is the first to our knowledge to estimate and compare the quantum efficiency of the green and blue light.

It has been suggested that bilirubin photodegradation with green light is mainly achieved through formation of lumirubin, ${ }^{5}$ but the binding of fatty acids to albumin has a definite effect on the absorption spectrum of bilirubin, shifting it towards longer wavelengths. ${ }^{6}$ In addition we have shown (unpublished data) in in vitro studies using aqueous solutions of bilirubin bound to albumin exposed to green or blue light, that the higher the concentration of bilirubin the larger the overlapping between the absorption spectrum of bilirubin and the emission spectrum of the green fluorescent lamps. Clinically green light may result in greater peripheral vasodilation and increased skin perfusion (because of its greater thermal energy) than the blue light, resulting in a greater part of the total bilirubin load being exposed to its effect.

We conclude that green light could be used for the treatment of neonatal jaundice as it is as effective as blue light, and is possibly less potentially harmful to both babies and nurses. ${ }^{7}$ Although green light is clinically effective, we recommend that studies specifically designed to elucidate its mode of action on bilirubin and fully evaluate its biological effect should be carried out.

This research project was supported in part by grants from the National Scholarships Foundation, Athens, Greece. We thank Professor C Papadatos, Head of the 2nd Department of Pediatrics, for his support and encouragement.

\footnotetext{
References

1 Vecchi C, Donzelli GP, Migliorini MG, Sbrana G. Green light in phototherapy. Pediatr Res 1983;17:461-3.
} 
2 Sideris EG, Papageorgiou GC, Charalampous SG, Vitsa EM. Aspectrum response study on single strand DNA breaks, sister chromatid exchanges and lethality induced by phototherapy lights. Pediatr Res 1981;15:1019-23.

${ }^{3}$ Schwartz AL, Cole FS, Fiedorek F, et al. Effect of phototherapy on sister chromatid exchange in premature infants. Lancet 1978;ii:157-8.

${ }^{4}$ Vecchi C, Donzelli GP, Sbrana G, Pratesi R. Phototherapy for neonatal jaundice: clinical equivalence of fluorescent green and special blue lamps. J Pediatr 1986;108:452-6.

5 Ennever JF, Knox I, Speck WT. Differences in bilirubin isomer composition in infants treated with green and white light phototherapy. J Pediatr 1986;109:119-21.
6 Jacobsen J, Brodersen R. Albumin-bilirubin binding mechanism. Kinetic and spectroscopic studies of binding of bilirubin and xanthobilirubic acid to human serum albumin. $J$ Biol Chem 1983;258:6319-26.

${ }^{7}$ Ham WT, Muller HA, Puffolo T. Sensitivity of the retina to radiation damage as a function of wavelength. Photochem Photobiol 1979;29:735-43.

Correspondence to Dr Hani Ayyash, 2nd Department of Paediatrics, University of Athens, Aglaia Kyriakou, Children's Hospital TT, Athens, 115 27, Greece.

\title{
Indicators of malnutrition in leukaemic children
}

\author{
M S KIBIRIGE, P H MORRIS JONES, AND R F STEVENS \\ Department of Oncology, Royal Manchester Children's Hospital, Manchester
}

SUMMARY In 24 children with acute leukaemia a low serum albumin concentration ( $31 \mathrm{~g} / \mathrm{l}$ or less) and a median weight:height ratio of less than 0.95 on admission were indicators of severe weight loss.

Malnutrition is a problem in children with cancer. Severe weight loss and malnutrition as causes of morbidity and mortality were quantified by Cahill, who established that the loss of $30 \%$ of lean body weight was incompatible with life. ${ }^{1}$ There are many causes of cancer cachexia. Patients with leukaemia are often affected, and both acute weight loss at presentation and persistent malnutrition are commonplace. Acute weight loss may be due to anorexia, malabsorption, excessive energy loss, ineffective metabolic activity, chemotherapy, and psychosocial factors. Whatever the causes, children who are malnourished when treatment is started have a worse prognosis than their counterparts who are well nourished. ${ }^{2-4}$ This may be due to factors inherent in the disease, or may be the result of ineffective treatment being given while waiting for their nutritional state to improve. In this retrospective study we tried to find out the risk factors that would help predict which children would benefit from supplementary nutrition.

\section{Patients and methods}

Twenty four new patients with acute leukaemia aged between 1.2 and 14.8 years were studied. They were retrospectively divided into two groups of 12 children. Group I comprised four boys and eight girls who needed supplementary riutrition. In Group II were 10 boys and two girls who did not need supplementary nutrition. On admission all children had a standard physical examination including measurement of height and weight. All children were treated according to the protocol of the Medical Research Council Childhood Leukaemia Trial. During their stay in hospital they were weighed regularly. The parents were advised by the dietician on what to give their children to eat. The children were offered food from the hospital kitchen, but parents provided alternative foods if the children requested items that were not available. During the course of treatment, if a child lost more than $10 \%$ of the admission weight he or she was given either nasogastric Fortisan 2.09 MJ (500 kcal)/500 ml by nasogastric tube or total parenteral nutrition. Total parenteral nutrition was given to those who were too ill to tolerate nasogastric feeds or who were unlikely to benefit from enteral feeding because of diarrhoea and malabsorption.

On admission (in addition to the other recommended haematological and biochemical tests) serum albumin concentration was estimated, and this was monitored weekly thereafter. The data obtained were used to determine which group of children required supplementary nutrition during the course of their treatment and to find out if there were any features apparent on admission that would predict which children would need nutritional support. The median weight:height ratio was calculated as the ratio of weight over height divided by weight over height at the 50 th centile. ${ }^{5}$ The ratio may be expressed as a percentage. The paired $t$ test was used to analyse the results. 